\title{
Anaemia is of prognostic significance in patients with oesophageal adenocarcinoma
}

\author{
${ }^{1}$ I Tanswell, ${ }^{2} \mathrm{H}$ Steed, ${ }^{3} \mathrm{~J}$ Butterworth, ${ }^{4} \mathrm{G}$ Townson \\ ${ }^{1}$ Consultant in Acute Medicine and Gastroenterology, ${ }^{2}$ Gastroenterology SpR; ${ }^{3,4}$ Consultant Gastroenterologists; Gastroenterology Department, \\ The Princess Royal Hospital, Telford, Shropshire, UK
}

\begin{abstract}
Anaemia is common in a wide range of malignancies and individual studies have demonstrated it to be an independent prognostic marker for survival in certain cancer types. The study population consisted of I7I patients: 77 anaemic and 94 non-anaemic. Sixty per cent of the study population had adenocarcinoma with $37 \%$ having squamous cell carcinoma. Late-stage disease occurred in $80 \%$ of individuals. There was no significant difference in survival times between the two groups $(p=0.1)$, and after adjusting for confounding factors including age, sex, stage and physical status $(p=0.8)$. Anaemic individuals with adenocarcinoma suffered a poorer survival probability compared to those with normal haemoglobon level $(p=0.02)$. Anaemia is common at diagnosis in oesophageal cancer and was found to be a significant prognostic indicator of survival in adenocarcinoma, but not squamous cell carcinoma.
\end{abstract}

KEYWORDS Adenocarcinoma, anaemia, oesophageal cancer, survival

DECLARATION OF INTERESTS These data were presented as a poster and abstract at United Gastroenterology Week in 2010.

Correspondence to I Tanswell, The Gastroenterology Department, The Princess Royal Hospital, Apley Castle, Telford, Shropshire, UK

tel. +44 (0) I952 64I 222

e-mail ian.tanswell@sath.nhs.uk

\section{INTRODUCTION}

Oesophageal cancer is the ninth most common cancer in the UK and the sixth worldwide, with a UK annual incidence of approximately 8,000.' Over the last three decades the incidence has increased, particularly in men, and much of this can be attributed to an increase in oesophageal adenocarcinoma (AC), which is now the dominant histological subtype. ${ }^{2}$ Unfortunately, prognosis remains poor with a five-year survival rate of $8 \%{ }^{3}$

Anaemia is common in a wide range of malignancies. Several mechanisms cause anaemia in colorectal cancer (CRC), including gastrointestinal haemorrhage, bone marrow infiltration, haemolysis, myelosuppression secondary to therapy and cancer-related anaemia (CRA). ${ }^{4}$ Cancer-related anaemia is characterised by normochromic and normocytic red cell indices, a form of anaemia seen in chronic illness ('anaemia of chronic inflammation'). It occurs secondary to tumour-induced activation of the immune system with the subsequent release of cytokines such as neopterin, tumour necrosis factor, interleukin-I and interferon- $\gamma{ }^{4}$ They inhibit red cell formation and hasten their removal through the reticuloendothelial system.

Anaemia has been shown to be a negative prognostic marker of survival, independent of tumour stage in a wide range of malignant diseases including CRC. ${ }^{4,5}$ The strongest association appears to occur in individuals receiving radiotherapy. ${ }^{4}$ Proposed mechanisms included tumour hypoxia in anaemic patients that reduces the availability of oxygen free radicals to exert one of the therapeutic effects of radiotherapy. Tissue hypoxia also promotes tumour angiogenesis and is associated with increased tumour aggressiveness and outcome possibly independent of treatment modality. ${ }^{6}$

\section{AIM}

To investigate anaemia as an independent prognostic factor in carcinoma of the oesophagus.

\section{METHODS}

\section{Patients}

All patients investigated and diagnosed with oesophageal cancer at two centres (Shrewsbury and Telford NHS Trust) between the years 2003 to 2006 were eligible for entry into this study. Data were collated retrospectively from patient notes based on long-term records kept by the upper gastrointestinal cancer multidisciplinary team.

\section{Inclusion and exclusion criteria}

Inclusion criteria required were endoscopic and/or histological confirmation of the diagnosis. Cancers arising at, or just below, the gastro-oesophageal junction with minimal involvement of the oesophagus were considered as gastric cancers and excluded from the analysis. All participants had a minimum of 12 months follow-up. 
TABLE I Demographic, clinical and tumour characteristics of the study population

\begin{tabular}{|c|c|c|c|}
\hline Median [range] & $\begin{array}{l}\text { Low } \\
\text { haemoglobin } \\
\text { [n=77] } \\
\text { I I.0 [5-|2.9] }\end{array}$ & $\begin{array}{l}\text { Normal } \\
\text { haemoglobin } \\
{[n=94]} \\
\text { I4.3 [ } 3-\mid 8.5]\end{array}$ & \\
\hline & $\begin{array}{c}\text { No. of } \\
\text { patients }\end{array}$ & $\begin{array}{c}\text { No. of } \\
\text { patients }\end{array}$ & $\mathbf{p}$ \\
\hline \multicolumn{4}{|l|}{ Age } \\
\hline Median range & 74.0 [38-90] & 66.5 [28-90] & 0.013 \\
\hline \multicolumn{4}{|l|}{ Sex } \\
\hline Male & 45 & 67 & NS \\
\hline Female & 32 & 27 & NS \\
\hline \multicolumn{4}{|l|}{ Histology } \\
\hline Adenocarcinoma & 41 & 56 & NS \\
\hline Squamous cell & 35 & 32 & NS \\
\hline Undifferentiated & 1 & 3 & NS \\
\hline Small cell $\mathrm{Ca}$ & 0 & 1 & NS \\
\hline Neuroendocrine & 0 & 2 & NS \\
\hline \multicolumn{4}{|l|}{ Grade } \\
\hline GI & 3 & 3 & NS \\
\hline G2 & 29 & 26 & NS \\
\hline G3 & 34 & 51 & NS \\
\hline G4 & 1 & 0 & NS \\
\hline GX & 8 & 8 & NS \\
\hline Non biopsy & 2 & 6 & NS \\
\hline \multicolumn{4}{|l|}{ Stage } \\
\hline 0 & 0 & 0 & NS \\
\hline 1 & 0 & 2 & NS \\
\hline 2 & 10 & 16 & NS \\
\hline 3 & 24 & 27 & NS \\
\hline 4 & 22 & 33 & NS \\
\hline NK & 21 & 16 & NS \\
\hline
\end{tabular}

$\mathrm{g} / \mathrm{dl}=$ gram/decilitre

$\mathrm{Ca}=$ carcinoma

NS=Not significant

NK=Not known

\section{Haemoglobin}

According to the haemoglobin level at the time of diagnosis, patients were stratified to either the normal haemoglobin group or anaemic group measured in grams/decilitre $(\mathrm{g} / \mathrm{dl})$. Anaemia was diagnosed when the haemoglobin level was below the normal range for the investigating laboratory $(13 \mathrm{~g} / \mathrm{dl}$ in males and $\mathrm{ll} \mathrm{g} / \mathrm{dl}$ in females). Haematological indices of iron deficiency were a mean corpuscular volume (MCV) $<76 \mathrm{fl}$ and/or mean cell haemoglobin $(\mathrm{MCH})$ below $27 \mathrm{pg}$. Biochemical markers of iron deficiency were ferritin levels $<30 \mu \mathrm{g} / \mathrm{l}$ (normal range for investigating laboratory 30-300 $\mu \mathrm{g} / \mathrm{l}$ ).

\section{Location}

The site of the cancers were categorised according to the recognised Union for International Cancer Control (UICC) TNM classification.

\section{Survival}

Survival as an overall function was calculated from the date of diagnosis (time patient told of diagnosis) to the date of death or last confirmed date of survival.The study ceased on 3I October 2006 and hence survival time was censored if the study subject remained alive at this point i.e. they had not reached the endpoint of interest (death).

\section{Statistics}

Baseline characteristics were analysed using the one-way analysis of variance (ANOVA) method, with the exception of age, which was analysed using the MannWhitney $U$ test for non-Gaussian distributed data.

Survival curves were constructed by the Kaplan Meier method, which allows and includes patients still alive at the end of the study period, treating them as censored data, with significance testing by the non-parametric log rank test, which is equivalent to the Mantel-Haenszel test. The Cox proportional hazards model was utilised to look at the confounder model to determine whether the two groups, anaemic and non-anaemic differed after adjusting for age, sex, tumour staging and physical status.

\section{RESULTS}

\section{Patients}

A total of |7| patients were included, baseline characteristics are shown in Table I. Seventy-seven were anaemic and 94 had a normal haemoglobin level. The median age of initial presentation was significantly older in the anaemic sub-group (74 years vs 66.5 years, $\mathrm{p}=0.013$ Mann-Whitney $U$ Test). The overall male to female ratio (M:F) was I.9:I and a higher proportion of males had normal haemoglobin. With respect to tumour subgroups, the M:F ratio was $4.1: 1$ in those with $A C$ and $0.8: 1$ in those with squamous cell carcinoma (SCC).

A comparison of tumour types and position in Table 2 shows the majority of AC were distal in position (74/97, $76 \%$ ) while SCC were distributed more evenly throughout the oesophagus.

Out of a total population of I7I individuals, 4 I (24\%) were deemed eligible for curative treatment as they displayed localised disease only (non anaemic $=26$, anaemic $=15$ ). The majority received surgery as their curative option (39), with two receiving radical radiotherapy. The reasons for non-curative treatment in the remainder are listed in order of frequency: metastatic disease (34), comorbid disease (32), advanced local disease 
TABLE 2 Position of cancer according to histological subtype $^{7}$

\begin{tabular}{|l|c|c|c|}
\hline & AC & SCC & Other \\
\hline Upper & 4 & 24 & 0 \\
\hline Middle & 19 & 27 & 3 \\
\hline Lower & 74 & 16 & 4 \\
\hline
\end{tabular}

$\mathrm{AC}=$ Adenocarcinoma

$\mathrm{SSC}=$ Squamous cell carcinoma

(23), patient age (19), patient preference (15), previous malignancy (four) and clinician preference (three).

\section{Presenting features and duration}

All patients diagnosed with cancer were those that were referred for their symptoms. Data with respect to symptom duration were available in 158 individuals (92\%). The mean and median duration were 9.3 and 8 weeks respectively (range $\mathrm{I}-48$ weeks). Presenting symptoms and/or features are listed in order of frequency in Table 3. The most common presenting features were dysphagia, weight loss and abdominal pain: symptoms that suggest malignancy.

The ASA classification, ${ }^{8}$ used to assess physical fitness, was recorded on $15 \mathrm{I}$ patients with the following results: ASA $1=4$, ASA $2=50$, ASA $3=70$, ASA $4=25$ and ASA $5=2$.

\section{Survival rates}

Low haemoglobin versus normal haemoglobin: Fifty-eight (75\%) of the low haemoglobin group died, with a median survival of 217 days and a mean survival of 411 days. Sixty-two (66\%) of the normal haemoglobin group died, with a median survival of 352 days and a mean survival of 492 days. The log rank test demonstrated that there were no differences in survival times between the two groups ( $p$ value $=0.1$ ), Figure I. This non-significance persisted after taking into account confounding variables ( $p=0.17$, Cox regression).

Tumour subtype SCC: Within the tumour type SCC group, 35 had low haemoglobins and 32 had normal haemoglobins. Median survival was 208 and 191 days respectively and mean survival was 377 and $36 \mathrm{I}$ days respectively. There was no significant difference in survival between the two groups stratified by haemoglobin level ( $p=0.9$, Cox regression).

Tumour subtype AC: Within the AC group 4I had low haemoglobins and 56 had normal haemoglobins. Survival curves are shown in Figure 2. They had median survivals of $25 \mathrm{I}$ and 487 days respectively and mean survivals of 431 and 599 days respectively. This difference was statistically significant $(p=0.02)$, even after adjusting for the confounder model $(p=0.05)$.
TABLE 3 Primary presenting features of oesophageal malignancy in all patients, $n=158$

\begin{tabular}{|l|c|}
\hline \multicolumn{1}{|c|}{ Presenting feature } & $\%$ \\
\hline Dysphagia & $4 \mathrm{I}$ \\
\hline Progressive unintentional weight loss & 20 \\
\hline Abdominal pain & 7 \\
\hline $\begin{array}{l}\text { Dyspepsia (persistent unexplained } \\
>55 \text { yrs age) }\end{array}$ & 6 \\
\hline Persistent vomiting & 6 \\
\hline Abnormal barium swallow/CT & 5 \\
\hline Iron deficiency anaemia & 3 \\
\hline Gastro-oesophageal reflux & 2.5 \\
\hline Anorexia & 2.5 \\
\hline Odynophagia & $\mathrm{I.5}$ \\
\hline Nausea & $\mathrm{I}$ \\
\hline Regurgitation & $\mathrm{I}$ \\
\hline Chest pain & $\mathrm{I}$ \\
\hline Gastrointestinal haemorrhage & $\mathrm{I}$ \\
\hline Lymphadenopathy & $\mathrm{I}$ \\
\hline Venous thromboembolism & $<1$ \\
\hline Dyspnoea/stridor & $<1$ \\
\hline Jaundice & \\
\hline
\end{tabular}

$\mathrm{CT}=$ Computed tomography

\section{Treatment}

With respect to surgery, the mean and median survival were 714 and 706 days respectively. A total of 79 patients had stent placement with a median survival of 137 days.

\section{DISCUSSION}

Previous studies have found that the most common symptoms in the presentation of oesophageal cancer are dysphagia, weight loss, reflux, odynophagia and dyspnoea. ${ }^{9}$ The findings of this study were similar, with dysphagia and weight loss ranking as the most common primary presenting features.

Anaemia in oesophageal cancer has been associated with a reduced survival. A study of 85 patients with locally advanced oesophageal cancer treated with chemoradiotherapy showed that a haemoglobin $>13 \mathrm{~g} / \mathrm{dl}$ to be an independent prognostic factor for better survival. For each unit increase the risk of death decreased by $5 \% .^{10}$ An investigation of 124 patients treated with radiotherapy or chemoradiotherapy (CRT) for oesophageal cancer found that pre-treatment 


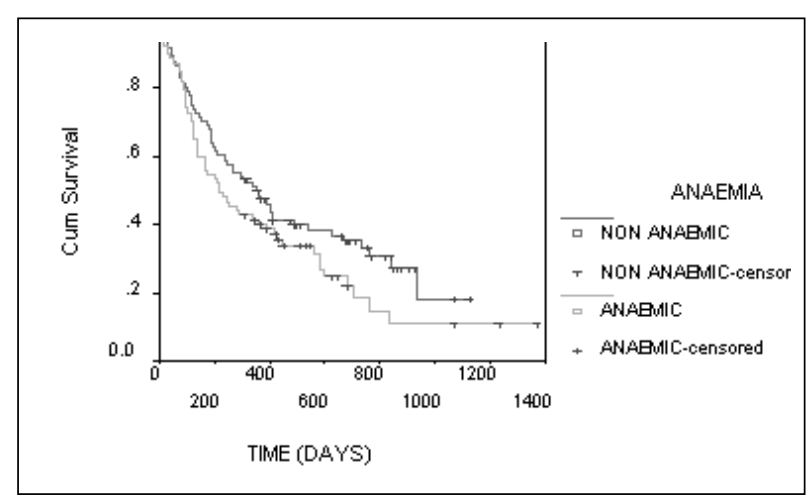

FIGURE I Survival curves showing cumulative survival according to haemoglobin status, with subdivision of the censored patients marked on the curve, i.e. patients still alive at the end of the study, (log rank $p=0.1$, Cox regression for confounding factor $p=0.17$ ). Mean survival of anaemic group 4 II days compared to 492 days in other group.

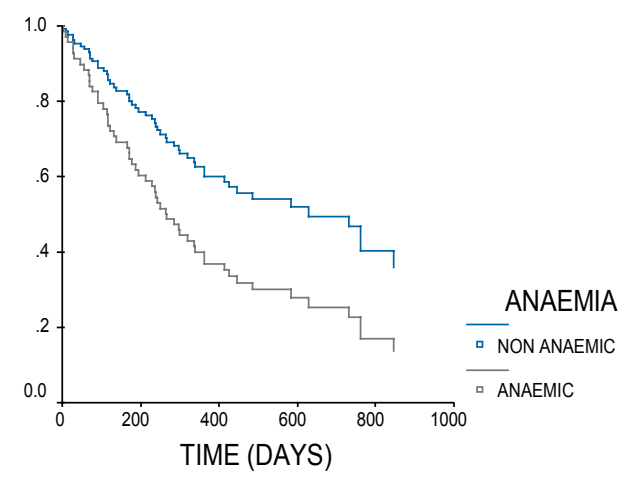

FIGURE 2 Survival curves according to the presence of anaemia in the histological subtype adenocarcinoma, $p=0.05$ after adjustment for confounding factors, mean survival of anaemic group 431 days compared to 599 days of nonanaemic group.

haemoglobin levels of $12.1-14 \mathrm{~g} / \mathrm{dl}$ were associated with the best overall survival, followed by $>14 \mathrm{~g} / \mathrm{dl}$ and then $<12 \mathrm{~g} / \mathrm{dl}(\mathrm{p}<0.00 \mathrm{l}) .{ }^{.1} \mathrm{~A}$ retrospective investigation of prognostic value of haemoglobin during radiochemotherapy of 108 patients found that haemoglobin levels of greater than $12 \mathrm{~g} / \mathrm{dl}$ was associated with significantly increased overall survival rates $(p=0.002) .^{12}$

Studies looking at anaemia in histological subtypes of oesophageal carcinoma have tended to focus on squamous cell carcinoma with slightly mixed results. These include a small study of 48 patients with T4/MI SCC oesophageal cancer who were treated with chemoradiotherapy. ${ }^{13}$ Pre-treatment haemoglobin of $<13 \mathrm{~g} / \mathrm{dl}$ was associated with a prognostic hazard ratio of $0.45(p=0.04)$. A large study of 243 patients with SCC undergoing chemoradiotherapy found that 60 were anaemic and the five-year survival was significantly reduced in the anaemic group $(p=0.001) .{ }^{14} A$ small investigation of anaemia at baseline pre-treatment in 46 SCC patients failed to show any association with a reduced outcome, while in the same group, a chemotherapy-induced anaemia and particularly those requiring blood transfusions during treatment was associated with a reduced overall survival $(p=0.046$ and $\mathrm{p}=0.07){ }^{15}$ Our study included 67 patients with oesophageal SCC and also found no association between pre-treatment anaemia and survival. These results conflict with the larger published studies and may simply be a reflection of the small numbers of patients included in the studies, but they are data added to the subject and a meta-analysis would be the next logical step to clarify the situation.

Only one small study looks at the AC histological subtype. Twenty-six patients with adenocarcinoma demonstrated an association between anaemia and reduced survival. ${ }^{16}$ These results are supported by our findings that in a group of 97 patients with oesophageal AC, anaemia was associated with a poorer survival $(p=0.05)$.

It has been repeatedly demonstrated in multiple studies that haemoglobin is a significant independent prognostic factor in oesophageal cancer, all be it in patients treated with chemotherapy or radiotherapy. ${ }^{10,11,14,16}$ However most studies are small, many focus on the SCC subtype and a meta-analysis is required to review and clarify the use of haemoglobin as a prognostic factor pre-treatment and during treatment. This analysis fails to demonstrate an association between baseline anaemia and reduced overall survival in the SCC subtype, which supports the findings of Hofheink et al. ${ }^{15}$

One small study of 56 patients given combined CRT for unresectable oesophageal cancer found $30 \%$ of these patients were given blood transfusions during CRT. ${ }^{17}$ Multivariate analysis showed the use of blood transfusion was associated with an improved overall survival $(p=0.01)$.

In another small study of 22 patients, erythropoeitin has been successfully used during neoadjuvant chemotherapy for locally advanced oesophageal adenocarcinoma to significantly increase haemoglobin levels to $12.6 \mathrm{~g} / \mathrm{dl}(\mathrm{p}<0.00 \mathrm{I}) .^{18}$

Anaemia in oesophageal cancer has been associated with poorer prognosis, but the results in SCC subtype have been mixed. Our results add to the literature failing to show an association with anaemia and poor prognosis and in particular in the SCC histological subtype. This may be due to low numbers, or the fact that the study is limited to one area and a meta-analysis would help clarify the issue. This study is only the second that we are aware of which reviews the outcome of anaemia in the AC subtype and confirms that anaemia is associated with a poorer survival. Given 
there is some evidence to support treatment of anaemia in improving survival, prospective studies are needed to ascertain whether transfusions or erythropoietin use can improve overall survival and if so, when during the treatment process this correction should occur and what haemoglobin level is required to see a benefit.

\section{REFERENCES}

I Ries LA, Eisner MP, Kosary CL et al, editors. SEER Cancer Statistics Review, 1975-2002. Bethesda: National Cancer Institute; 2005.

2 Schlansky B, Dimarino AJ, Loren D et al. A survey of oesophageal cancer:pathology, stage and clinical presentation. Aliment PharmacolTher 2006; 23:587-93. doi: I0.I I I I/j. I365-2036.2006.02782.x

3 Office for National Statistics, 2009.

4 Clarke $\mathrm{H}$, Pallister $\mathrm{CJ}$. The impact of anaemia on outcome in cancer. Clin Lab Haematol 2005; 27:1-13. doi:I0. I I I I/j.I365-2257.2004.00664.x

5 Knight K,Wade S, Balducci L. Prevalence and outcomes of anaemia in cancer: a systematic review of the literature. Am J Med 2004; | |6: I Is-26s. doi:10.1016/j.amjmed.2003.12.008

6 Dunst J, Pigorsch S, Hansgen G et al. Low haemoglobin is associated with increased serum levels of vascular endothelial growth factor (VEGF) in cancer patients. Does anaemia stimulate angiogenesis? Strahlenther Onkol 1999; 175:93-96. doi:10.1007/ BF02742340

7 In:Sobin LH,Wittkind CH editors.TNM Classification of Malignant Tumours. Anatomical localisation of the oesophagus (UICC). 5th edition. New York:Wiley-Liss; 1997. p. 54-58.

8 The American Society of Anaesthesiologists' physical status classification system. American Society of Anaesthesiologists [cited 2006]. Available at: http://www.asahq.org/clinical/ physicalstatus.htm

9 Daly JM, Fry WA, Little AG et al. Esophageal cancer: results of an American College of Surgeons Patient Care Evaluation Study. J Am Col Surg 2000; 190:562-72. doi:I0.10I6/SI072-75I5(00)00238-6

I0 Valencia Julve J, Alonso Orduña V, Escó Barón R et al. Influence of haemoglobin levels on survival after radical treatment of esophageal carcinoma with radiotherapy. Clin Transl Oncol 2006; 8:22-30. doi: |0.1007/s |2094-006-009|-z

I I Rades D, Schild SE, Bahrehmand R et al. Prognostic factors in the nonsurgical treatment of esophageal carcinoma with radiotherapy or radiochemotherapy: the importance of pre-treatment hemoglobin levels. Cancer 2005; 103: I 740-46. doi:10.1002/cncr.20952

\section{ACKNOWLEDGEMENT}

We would like to thank S Ahmad for helping to collect the data.

I2 Rades D, Lang S, Schild SE et al. Prognostic value of haemoglobin levels during concurrent radio-chemotherapy in the treatment of oesophageal cancer. Clin Oncol 2006; 18:139-44. doi:10.1016/j. clon.2005.10.007

I3 Zenda S, Hironaka S, Boku N et al. Impact of haemoglobin level on survival in definitive chemoradiotherapy for T4/MI lymph node esophageal cancer. Dis Esophagus 2008; 21:195-200. doi: I0. I I I I/j. I 442-2050.2007.00750.x

I4 Zhao KL, Liu G, Jiang GL et al.Association of haemoglobin level with morbidity and mortality of patients with locally advanced oesophageal carcinoma undergoing radiotherapy - a secondary analysis of three consecutive clinical phase III trials. Clinical Oncology 2006; 18:621-27. doi:10.1016/j.clon.2006.04.015

I5 Hofheinz RD, Raab B, Mai S et al. Impact of chemoradiotherapyinduced anaemia on survival in uniformly staged patients with locally advanced squamous cell carcinoma of the esophagus. Onkologie 2004; 27:4626-6. doi: I0.II59/000080366

16 Voelter V, Schumacher C, Busch R et al. Incidence of anaemia in patients receiving neoadjuvant chemotherapy for locally advanced esophagogastric cancer. Ann Thorac Surg 2004; 78:1037-4I. doi:10.1016/j.athoracsur.2004.01.049

17 Kader AS, Lim JT, Berthelet E et al. Prognostic significance of blood transfusions in patients with esophageal cancer treated with combined chemoradiotherapy. Am J Clin Oncol 2007; 30:492-97. doi:I0.1097/0I.coc.0000264I77.66369.18

18 Abbrederis K, Bassermann F, Schuhmacher C et al. Erythropoietinalfa during neoadjuvant chemotherapy for locally advanced esophagogastric adenocarcinoma. Ann Thorac Surg 2006; 82:292-97. doi:10.1016/j.athoracsur.2006.01.097 